\title{
Teaching and Assesing Graduate AtTributes in CoOperative EdUCATION
}

\author{
Darlene Spracklin-Reid \\ Memorial University \\ darlenesr@mun.ca
}

\begin{abstract}
The Faculty of Engineering and Applied Science at Memorial University has a long and rich history of cooperative education. Our students have benefited from this type of experiential learning and the skills they acquire contribute to the development of graduate attributes. To support this process and document it for the purposes of accreditation, Memorial University is embarking on a technology-based approach to support students as they develop and apply professionalism, teamwork and communication skills in a workplace setting. This approach is based on sound teaching and learning practice, including a just-in-time approach to the delivery of instruction and using formative and summative assessment techniques.
\end{abstract}

\section{INTRODUCTION}

In 2010, the Canadian Engineering Accreditation Board (CEAB) began reviewing programs for progress toward assessment of graduate attributes [1]. This represented a significant change from traditional inputsbased to outcomes-based accreditation. Work terms play an essential role in demonstrating that students at Memorial University have acquired the specified skills and attitudes required to practice as a professional engineer in Canada.

Graduate attributes are program outcomes. They represent what a student will know, be able to do and the attitudes they will possess upon graduation. Program outcomes are a compilation of learning outcomes; therefore, the graduate attributes are built upon a foundation of learning outcomes from both academic and work terms. Through the assessment of these outcomes, graduate attributes are assessed.

\section{TEACHING, LEARNING AND ASSESSMENT USING ONLINE TOOLS}

With the rich learning environment that work terms provide, it is important to capture the learning outcomes through authentic assessment. At Memorial University, the Faculty of Engineering and Applied Science has been collaborating with the Distance Education, Learning and Teaching Support (DELTS) division to develop learning outcomes and assessments, and linking them to the graduate attributes in order to demonstrate that students have acquired these essential skills and attitudes.

While many of the graduate attributes are assessed in academic courses, work terms are also essential in their development, including communication, teamwork and leadership, professionalism, ethics and equity and lifelong learning. New approaches to teaching and assessment are being developed for work terms to measure identified learning outcomes associated with these graduate attributes. These assessment techniques include structured reflection, ePortfolios, and cross-discipline debriefing sessions, supported by online professional development modules.

The Faculty has been working with DELTS to pilot an e-portfolio approach to managing a long-term view of each student's progress in achieving the desired graduate attributes. By identifying clear rubrics to measure progress, combined with periodic review and coaching, students will be responsible for demonstrating their own 'professionalization'. Work terms are an essential component of the ePortfolio - they provide an opportunity for students to have experiences to reflect upon and opportunities to grow as a result of the reflective process. Their structured reflections will be drawn into the ePortfolio to demonstrate the growth of their graduate attributes, particularly those that require an experiential and reflective approach for meaningful learning to occur.

Student learning over four work terms, as identified through stated work term learning outcomes, will be enhanced by the completion of required online professional development modules. These modules will focus on teaching and developing graduate attributes as required by the Canadian Engineering Accreditation Board. These modules will be tied to the ePortfolio, allowing students to present their work, the associated assessment and their reflections.

\section{References}

[1] Engineers Canada, Canadian Engineering Accreditation Board, "2010 Accreditation Criteria and Procedures", www.engineerscanada.ca, 2010. 